\title{
Barium Metaplumbate Thin Film Electrodes for Ferroelectric Devices
}

\author{
A. I. MARDARE, ${ }^{1}$ C. C. MARDARE, ${ }^{1}$ E. JOANNI,,${ }^{1,2}$ \\ J. R. A. FERNANDES,${ }^{1,2}$ P. M. VILARINHO ${ }^{3}$ and A. L. KHOLKIN ${ }^{3}$ \\ ${ }^{1}$ INESC-Porto, Unidade de Optoelectrónica e Sistemas Electrónicos - 4169-007, \\ Porto, Portugal \\ ${ }^{2}$ Departamento de Física, Universidade de Trás-os-Montes e Alto Douro - UTAD, 5001-911, \\ Vila Real, Portugal \\ ${ }^{3}$ Departamento de Engenharia Cerâmica e do Vidro, CICECO, Universidade de Aveiro, \\ 3810-193, Aveiro, Portugal
}

(Received September 4, 2002; In final form December 15, 2002)

\begin{abstract}
Barium metaplumbate thin films were deposited in situ by pulsed laser deposition on $\mathrm{Si} / \mathrm{SiO}_{2}$ and $\mathrm{Si} / \mathrm{SiO}_{2} / \mathrm{Ti} / \mathrm{Pt}$ substrates between $400^{\circ} \mathrm{C}$ and $700^{\circ} \mathrm{C}$. Films prepared at low temperature $\left(\leq 500^{\circ} \mathrm{C}\right)$ over platinum were randomly oriented. For depositions made at $2 \times 10^{-2} \mathrm{mbar}$ of oxygen, the films were oriented (110) for all temperatures, while at $0.1 \mathrm{mbar}$ the films were oriented (110) at $500^{\circ} \mathrm{C}$, changing to a mixed $(222) /(200)$ orientation above $550^{\circ} \mathrm{C}$. The conductivity of $\mathrm{BaPbO}_{3}$ reached values of $5.6 \times 10^{-5} \Omega \mathrm{cm}$. The films deposited directly over silica were polycrystalline for temperatures above $500^{\circ} \mathrm{C}$, having a strong (110) orientation only at $700^{\circ} \mathrm{C}$. The orientation of $\mathrm{BaPbO}_{3}$ deposited either on silica or platinum, was reflected on the PZT films deposited at room temperature over $\mathrm{BaPbO}_{3}$ and crystallized by different thermal treatments. PZT capacitors made over $\mathrm{BaPbO}_{3}$ presented high values of remnant polarization (up to $44 \mu \mathrm{C} / \mathrm{cm}^{2}$ ).
\end{abstract}

Keywords: Laser ablation; thin films; conductive oxides; electrodes; capacitors; ferroelectric properties

\section{INTRODUCTION}

Barium metaplumbate $\mathrm{BaPbO}_{3}$ (abbreviated as BPO) is a useful material in many applications in microelectronics due to its metallic conduction behavior, with a low resistivity and a small positive temperature coefficient. Ikushima and Hayakawa [1] explained these phenomena as being derived from oxygen vacancies while Shannon and Bierstedt [2] considered the filled $\mathrm{d}$ bands of $\mathrm{Pb}^{4+}$ to be the real reason. Electrical and stability characteristics of BPO were studied in bulk ceramics by Hsieh and Fu [3]. 
A few results on BPO thin films deposited by RF magnetron sputtering have been recently reported by $\mathrm{Luo}$ and $\mathrm{Wu}$ [4], but no data has yet been published on BPO thin films made by pulsed laser deposition (PLD). The study of BPO thin films is important because of their possible application as electrodes in ferroelectric devices. The orthorhombic perovskite structure of BPO makes it suitable for being used as templates for growing thin films of ferroelectric materials with similar structure, like lead zirconate titanate (PZT). PZT thin films are used in capacitors for ferroelectric random access memories due to their nonvolatility and fast switching speed. However, the application of these ferroelectric capacitors is limited by the fatigue phenomenon, defined as the gradual decrease of the switching polarization with the number of switching cycles when platinum electrodes are used [5]. The mechanisms responsible for the fatigue phenomenon are still not fully understood, but electromigration of charged defects and/or charge injection into the ferroelectric film are probably involved [6].

Many efforts have been focused on retaining long term reliability of ferroelectric capacitors by finding optimal oxide electrode materials; $\mathrm{RuO}_{2}$, $\mathrm{La}_{1-\mathrm{x}} \mathrm{Sr}_{\mathrm{x}} \mathrm{CoO}_{3}, \mathrm{LaNiO}_{3}$ and other oxides associated with platinum have been proposed [7-9]. Oxide/PZT/oxide heterostructures have excellent resistance to polarization fatigue, but they usually have large leakage currents and are more susceptible to dielectric breakdown. $\mathrm{RuO}_{2}$ electrodes, for example, exhibit large and variable leakage currents $\left(10^{-4}-10^{-3} \mathrm{~A} / \mathrm{cm}^{2}\right.$ at $\left.1 \mathrm{~V}\right)$ [10]. Despite the good fatigue performance of PZT capacitors using $\mathrm{La}_{1-\mathrm{x}} \mathrm{Sr}_{\mathrm{x}} \mathrm{CoO}_{3}$ top and bottom electrodes, their remnant polarization is lower than that of $\mathrm{Pt} / \mathrm{PZT} / \mathrm{Pt}$ capacitors and they require high temperatures for crystallization heat treatment [11].

In the present work the pulsed laser deposition of $\mathrm{BPO}$ in situ on $\mathrm{Si} / \mathrm{SiO}_{2}$ and $\mathrm{Si} / \mathrm{SiO}_{2} / \mathrm{Ti} / \mathrm{Pt}$ substrates was investigated. The effects of different deposition conditions and heat treatments on the properties of the PZT films were also studied.

\section{EXPERIMENTAL DETAILS}

For obtaining $\mathrm{SiO}_{2}$ on $\mathrm{Si}$, the $\mathrm{Si}$ substrates were heated at $950^{\circ} \mathrm{C}$ for $72 \mathrm{~h}$ in wet $\mathrm{O}_{2}$ flow. $\mathrm{Ti}$ and $\mathrm{Pt}$ films were deposited using the RF sputtering technique in Ar with 2 in. diameter metal targets; the sputtering chamber had a base pressure of $10^{-6}$ mbar. Ti films $20 \mathrm{~nm}$ thick were deposited at room temperature using an RF power of $150 \mathrm{~W}$ and a deposition pressure of $10^{-2}$ mbar. The Pt films $200 \mathrm{~nm}$ thick were sputtered at $500^{\circ} \mathrm{C}$ with the same RF power and the same deposition pressure. 
The targets for laser ablation, $\mathrm{BPO}$ and PZT $(\mathrm{Zr} / \mathrm{Ti}$ ratio $=52 / 48)$, were $1.5 \mathrm{~cm}$ diameter dense ceramic disks. The ceramic powders were prepared by the conventional mixed oxide method. For the BPO targets, stoichiometric proportions of barium carbonate and lead oxide were mixed and calcined at $700^{\circ} \mathrm{C}$ for 2 hour, to obtain the pure BPO phase. For the PZT (52/48) targets, stoichiometric proportions of lead carbonate, zirconium and titanium oxide were mixed and calcined at $900^{\circ} \mathrm{C}$ for 1 hour, to form the pure PZT phase. Fine BPO and PZT powders $(<5 \mu \mathrm{m})$ were obtained after milling for several hours in a planetary mill. Circular pellets were prepared by uniaxially pressing at $200 \mathrm{MPa}$. In order to obtain dense BPO and PZT ceramics, the BPO samples were sintered in air between $800^{\circ} \mathrm{C}$ and $1000^{\circ} \mathrm{C}$ for 2 hour in the presence of BPO packing powder; the PZT samples were sintered at $1250^{\circ} \mathrm{C}$ for 2 hour, with a $\mathrm{O}_{2}$ flux and in the presence of lead zirconate packing powder.

Before depositing each film the chamber was evacuated until at least $10^{-7}$ mbar. For all the depositions, a KrF laser with energy of $200 \mathrm{~mJ}$ for a $10 \mathrm{~Hz}$ repetition rate and a fluence of $1.4 \mathrm{~J} / \mathrm{cm}^{2}$ was used. The $\mathrm{BPO}$ films were deposited in an $\mathrm{O}_{2}$ atmosphere at two different pressures: $1 \times 10^{-1} \mathrm{mbar}$ and $2 \times 10^{-2} \mathrm{mbar}$; the distance between target and substrate was $4 \mathrm{~cm}$ and the deposition time was 10 minutes. Under these conditions, the deposition rate of $\mathrm{BPO}$ was $45 \mathrm{~nm} / \mathrm{min}$.

Two series of BPO films were deposited in situ with different deposition conditions. The first series was made on $\mathrm{Si} / \mathrm{SiO}_{2} / \mathrm{Ti} / \mathrm{Pt}$ and the second one was deposited directly over $\mathrm{Si} / \mathrm{SiO}_{2}$. The temperatures for the depositions made over platinum ranged between $400^{\circ} \mathrm{C}$ and $700^{\circ} \mathrm{C}$ with a step of $50^{\circ} \mathrm{C}$ while the temperatures for the depositions over $\mathrm{Si} / \mathrm{SiO}_{2}$ ranged between $450^{\circ} \mathrm{C}$ and $700^{\circ} \mathrm{C}$ with a step of $50^{\circ} \mathrm{C}$. Without breaking the vacuum in the PLD chamber after deposition of BPO, the target was replaced with a PZT target $(\mathrm{Zr} / \mathrm{Ti}$ ratio $=52 / 48)$ and PZT films were deposited on top of BPO at room temperature with a deposition pressure of $2 \times 10^{-2} \mathrm{mbar}$ in $\mathrm{O}_{2}$. The energy of the laser was $300 \mathrm{~mJ}$ for a $10 \mathrm{~Hz}$ repetition rate and the deposition time was 30 minutes with a target-substrate distance of $4 \mathrm{~cm}$.

For crystallizing the PZT films, two methods were used: furnace annealing at $675^{\circ} \mathrm{C}$ for 15 minutes with heating and cooling rates of $50^{\circ} \mathrm{C} / \mathrm{min}$ and rapid thermal annealing (RTA) at $650^{\circ} \mathrm{C}$ with a heating rate of $20^{\circ} \mathrm{C} / \mathrm{sec}$. Aluminum top electrodes were deposited by thermal evaporation at a pressure of $10^{-6}$ mbar, using a shadow mask.

The thickness of the films was measured with a contact profilometer (Dektak II A) and they were structurally analyzed using optical and scanning electron microscopy (JEOL JSM-6301F) and X-ray diffraction (Siemens 
D5000). A system composed of an amplifier, a function generator (HP 8116A), an oscilloscope (LeCroy $9310 \mathrm{M}$ ) and a computer running a LabView program was used for recording the hysteresis loops. Electrical resistivity was measured on the $\mathrm{BPO}$ films deposited over both $\mathrm{Pt}$ and $\mathrm{SiO}_{2}$ using the four-probe technique.

\section{RESULTS AND DISCUSSION}

\subsection{BPO Films}

For the deposition of BPO films with stable properties it is important to use fully reacted targets sintered at high temperature. Figure 1 shows X-ray diffraction patterns for $\mathrm{BPO}$ targets sintered at $800^{\circ} \mathrm{C}$ and $1000^{\circ} \mathrm{C}$. One can see from the diffractograms that the target sintered at low temperature has residual barium and lead oxide peaks. Films made from this target were highly hygroscopic and in less than one minute the presence of a reacted layer could be observed on the surface of the films as shown on Fig. 2.
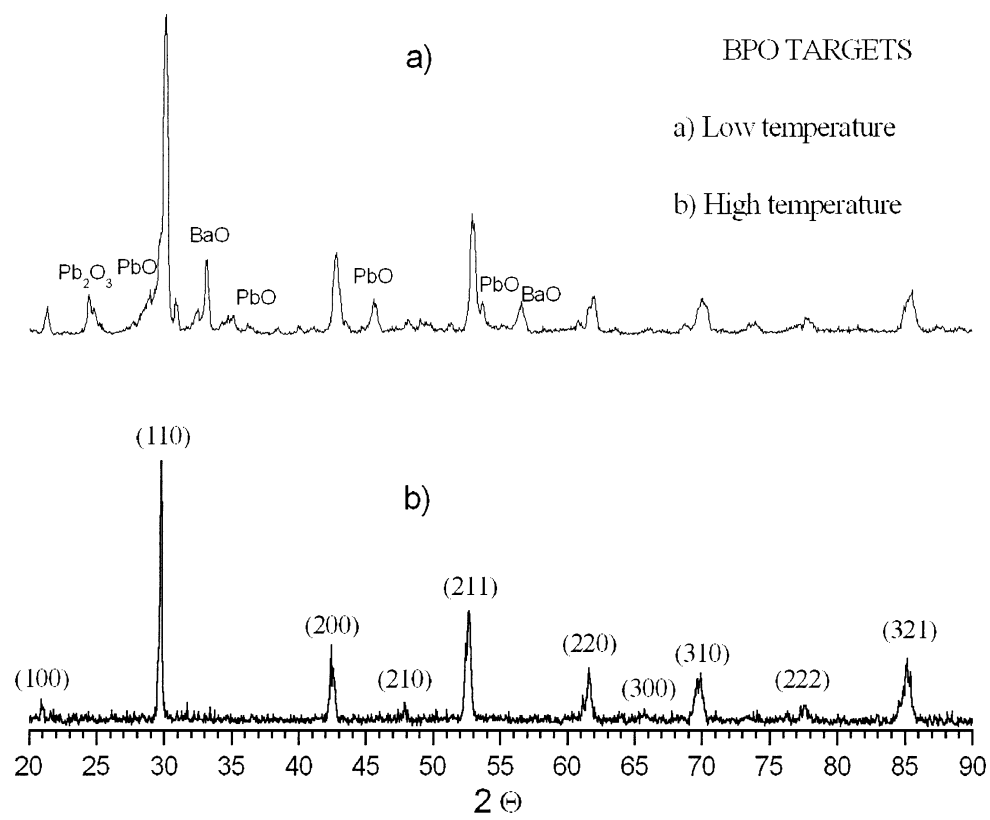

Figure 1. X-ray diffraction pattern of the BPO targets sintered below (a) and at (b) $1000^{\circ} \mathrm{C}$. 


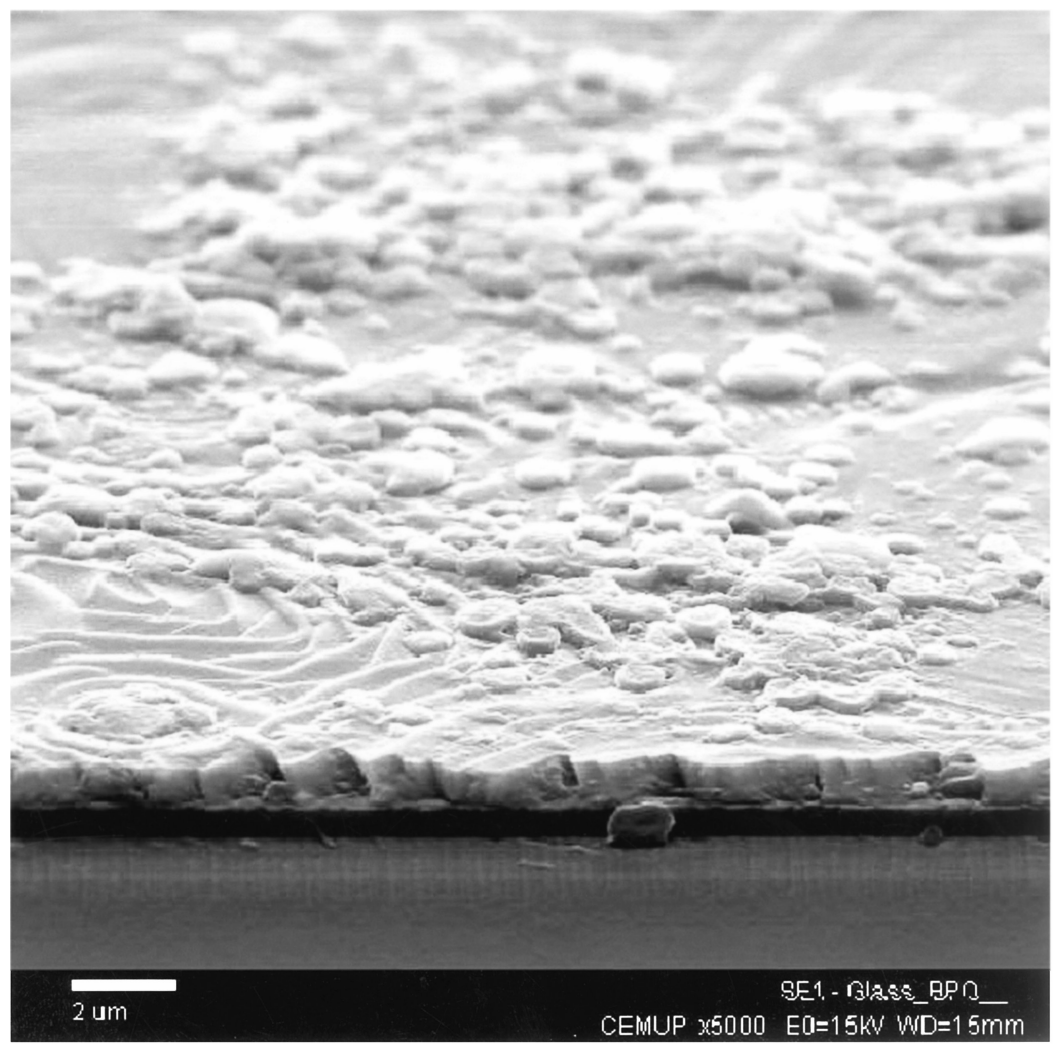

Figure 2. Reacted layer on the surface of BPO film due to atmospheric moisture.

The X-ray diffractogram of the BPO target sintered at $1000^{\circ} \mathrm{C}$ shows only the peaks from BPO and the films made from this target were immune to the atmospheric moisture. Figure 3 shows an optical micrograph of the surface of a film made at $600^{\circ} \mathrm{C}$ over platinum; the BPO films are black, smooth, uniform and no reactions could be detected, even after long term air exposure.

The BPO films made over Pt have shown a crystalline orientation dependent on the deposition temperature. In Fig. 4 the X-ray diffraction patterns for three significant temperatures are plotted. At $400^{\circ} \mathrm{C}$ the BPO is not crystallized yet; with the increase of the temperature, the BPO peaks start to appear and the films are randomly oriented. Increasing even more the deposition temperature, the preferred orientation starts to be $(110)$ at $500^{\circ} \mathrm{C}$ 


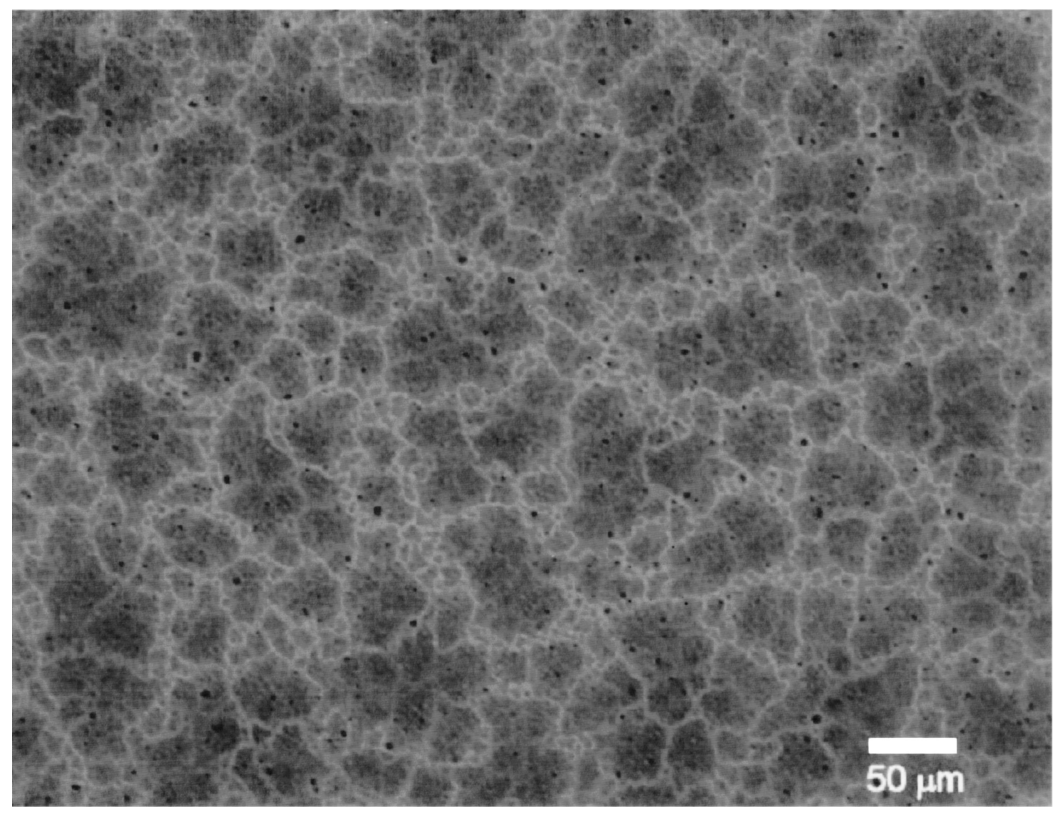

Figure 3. Surface of a BPO film made from target sintered at high temperature.

and the (222) peak appears. For higher temperatures the (222) peak and the $\langle 100\rangle$ peaks become important while the $\langle 110\rangle$ orientations are weaker. The (222) orientation is promoted by the platinum layer which is (111) oriented.

The effect of Pt is evident in the analysis of the BPO films made directly over $\mathrm{SiO}_{2}$ at the same deposition temperatures (Fig. 5). In the X-ray diffractograms of the films made without Pt one can see that the (222) orientation of $\mathrm{BPO}$ is not present for any deposition temperature. In this case the temperature for crystallizing the BPO is increased to values over $450^{\circ} \mathrm{C}$ due to the absence of crystalline orientation in the underlying silica. For temperatures higher then the crystallization temperature, the BPO films are oriented (110) and (100) for $600^{\circ} \mathrm{C}$, while at $700^{\circ} \mathrm{C}$ the film is strongly (110) oriented. In the absence of Pt all the temperatures needed for obtaining the different orientations in BPO films were increased by at least $50^{\circ} \mathrm{C}$.

Electrical resistivity was measured on the BPO films deposited over both $\mathrm{Pt}$ and $\mathrm{SiO}_{2}$. The BPO films deposited over platinum exhibited resistivities ranging between $1.1 \times 10^{-4} \Omega \mathrm{cm}$ and $5.6 \times 10^{-5} \Omega \mathrm{cm}$. For the BPO films deposited over silica the resistivities were between $2.5 \times 10^{-1} \Omega \mathrm{cm}$ and $3.6 \times 10^{-1} \Omega \mathrm{cm}$. For assessing the performance of BPO as bottom electrode 


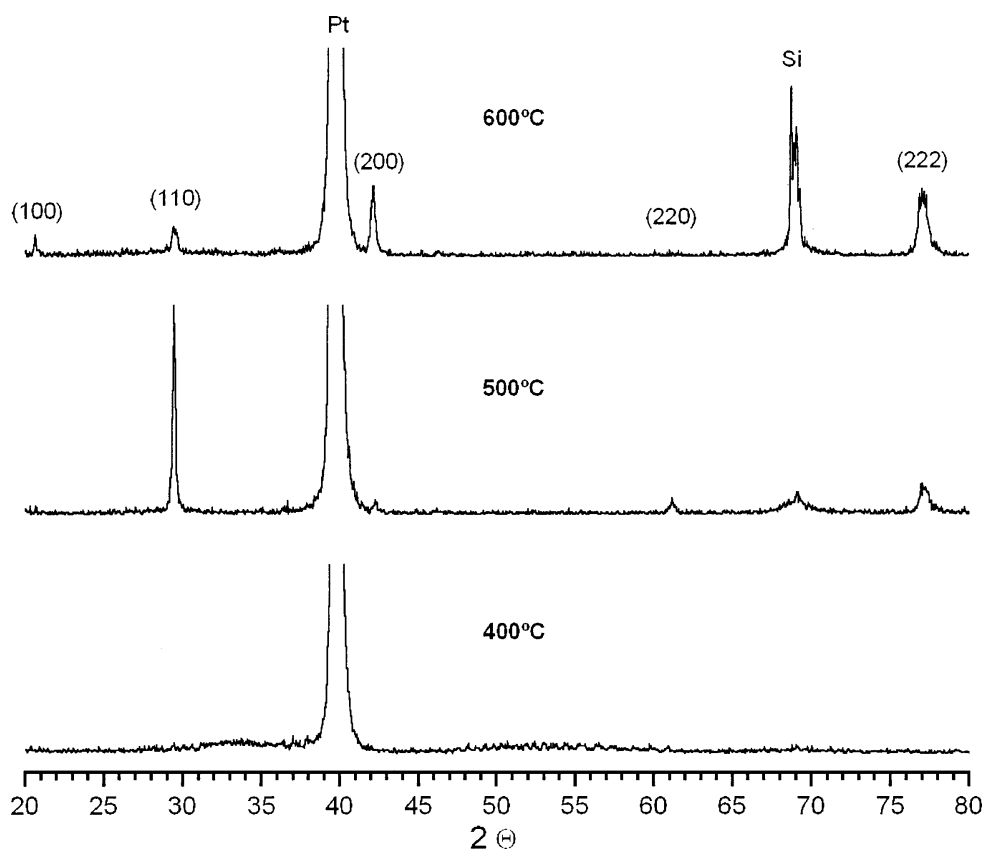

Figure 4. X-ray diffraction pattern of BPO films made over Pt.

in ferroelectric capacitors, PZT films were deposited by laser ablation on top of the BPO films.

\subsection{PZT Films}

The orientation of the BPO and PZT films after furnace crystallization of the PZT at $675^{\circ} \mathrm{C}$ was analyzed by X-ray diffraction (Figs. 6 and 7). In both graphs the families of planes are shown in brackets, and one can see that the peaks for BPO and PZT appear in pairs and their intensities are similar. Another important feature of the films made by laser ablation is the absence of peaks from pyrochlore, in contrast with the results reported by Luo and Wu on films made by sputtering in the same temperature range [4]. Figure 6 shows the X-ray diffraction pattern for the PZT crystallized over BPO made at $550^{\circ} \mathrm{C}$ and $10^{-1} \mathrm{mbar}_{2}$.

One can see clearly from the graph that the BPO is strongly oriented in the (222) direction and the PZT follows the BPO orientation, indicating epitaxial growth of the PZT. With the decrease of the deposition 


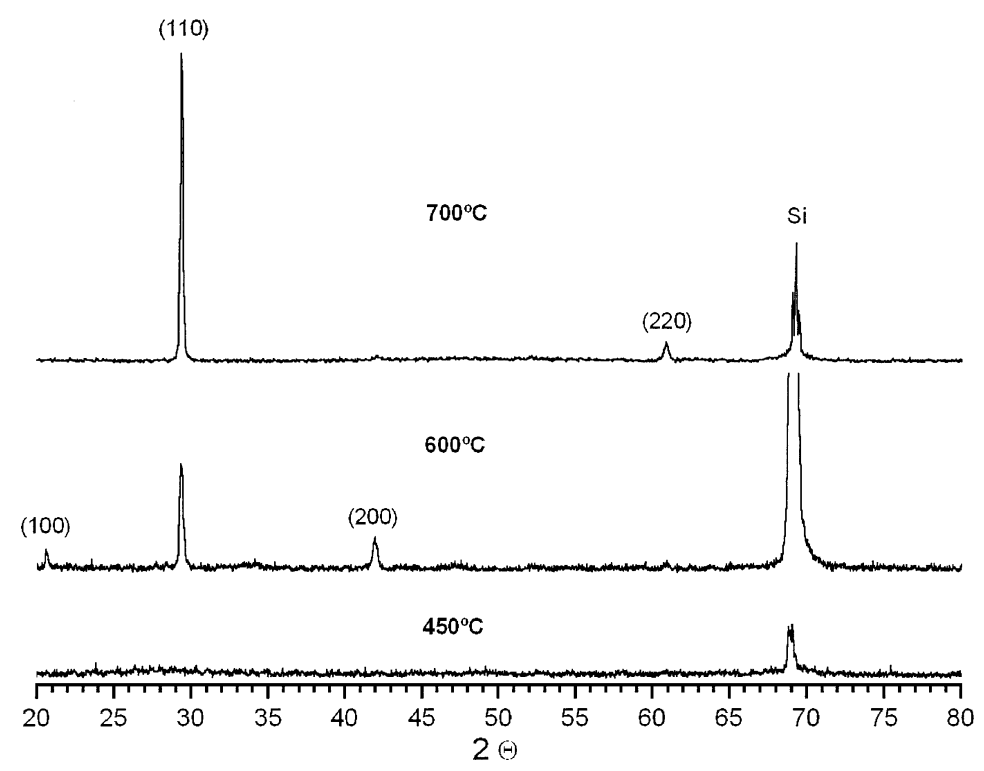

Figure 5. X-ray diffraction pattern of BPO films made over $\mathrm{SiO}_{2}$.
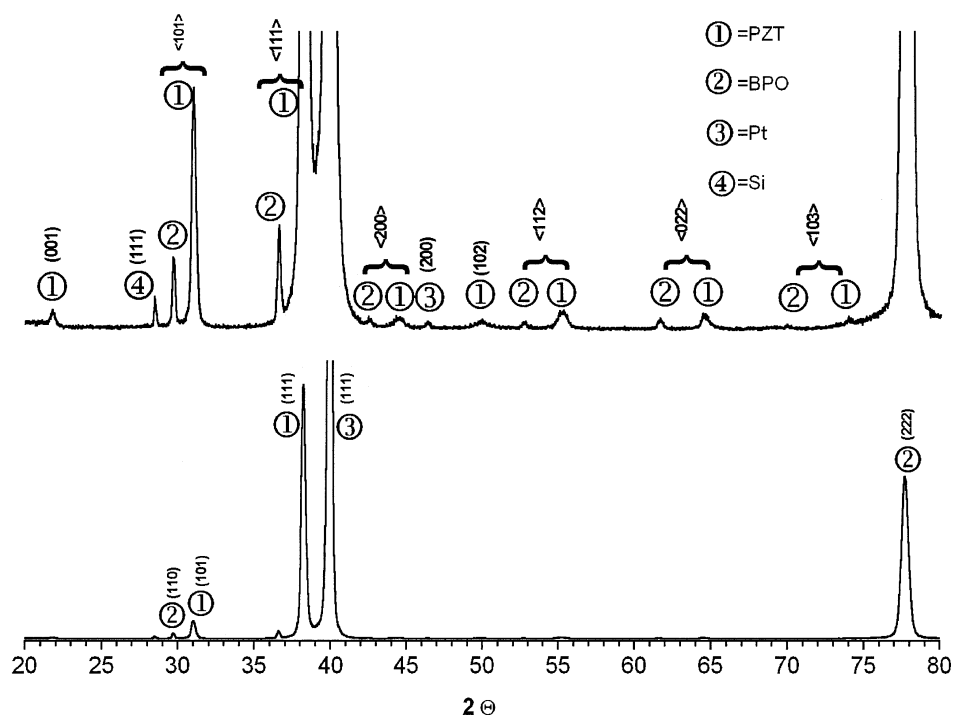

Figure 6. X-ray diffraction pattern for the PZT crystallized over BPO made at $550^{\circ} \mathrm{C}$ and $10^{-1} \mathrm{mbar}_{2}$. The upper graph is the same as the lower one but with the vertical scale increased. 


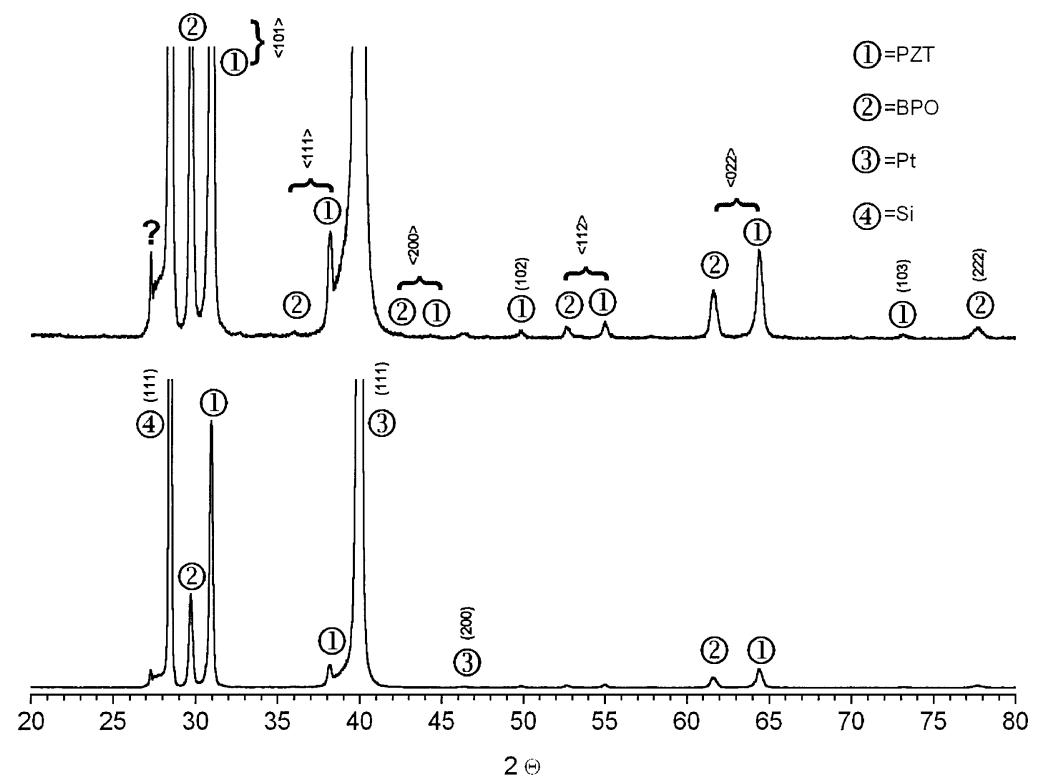

Figure 7. X-ray diffraction pattern for the PZT crystallized over BPO made at $550^{\circ} \mathrm{C}$ and $2 \times 10^{-2} \mathrm{mbar}_{2}$. The upper graph is the same as the lower one but with the vertical scale increased.

pressure of BPO the orientation changes to (110), as shown in Fig. 7, and again the PZT is following the same trend, in this case with a (101) orientation.

A PZT film deposited over $\mathrm{SiO}_{2} / \mathrm{BPO}$ and crystallized by RTA at $650^{\circ} \mathrm{C}$ is shown in Fig. 8. One can see that the BPO is adherent to silica and the surface of the PZT is smooth with grains of around $1 \mu \mathrm{m}$. The boundary between BPO and PZT films is clearly visible on the fracture.

Figure 9 shows the X-ray diffractograms for PZT films deposited over $\mathrm{SiO}_{2} / \mathrm{BPO}$ made in situ at $550^{\circ} \mathrm{C}$ and $650^{\circ} \mathrm{C}$ and crystallized by RTA at $650^{\circ} \mathrm{C}$. For BPO films made at $550^{\circ} \mathrm{C}$ both $\mathrm{BPO}$ and PZT are polycrystalline, without a dominant orientation, while for BPO films made at $650^{\circ} \mathrm{C}$ both $\mathrm{BPO}$ and PZT have orientations belonging to the $\langle 110\rangle$ family. The smaller peaks in the lower graph are all from the other orientations of BPO and PZT.

Ferroelectric properties were investigated for samples where the PZT was deposited over different types of electrodes: Pt/BPO, BPO and Pt. In Fig. 10 are shown the hysteresis loops for BPO deposited over $\mathrm{Pt}$ and PZT crystallized in the furnace at $675^{\circ} \mathrm{C}$ for $15 \mathrm{~min}$, BPO 


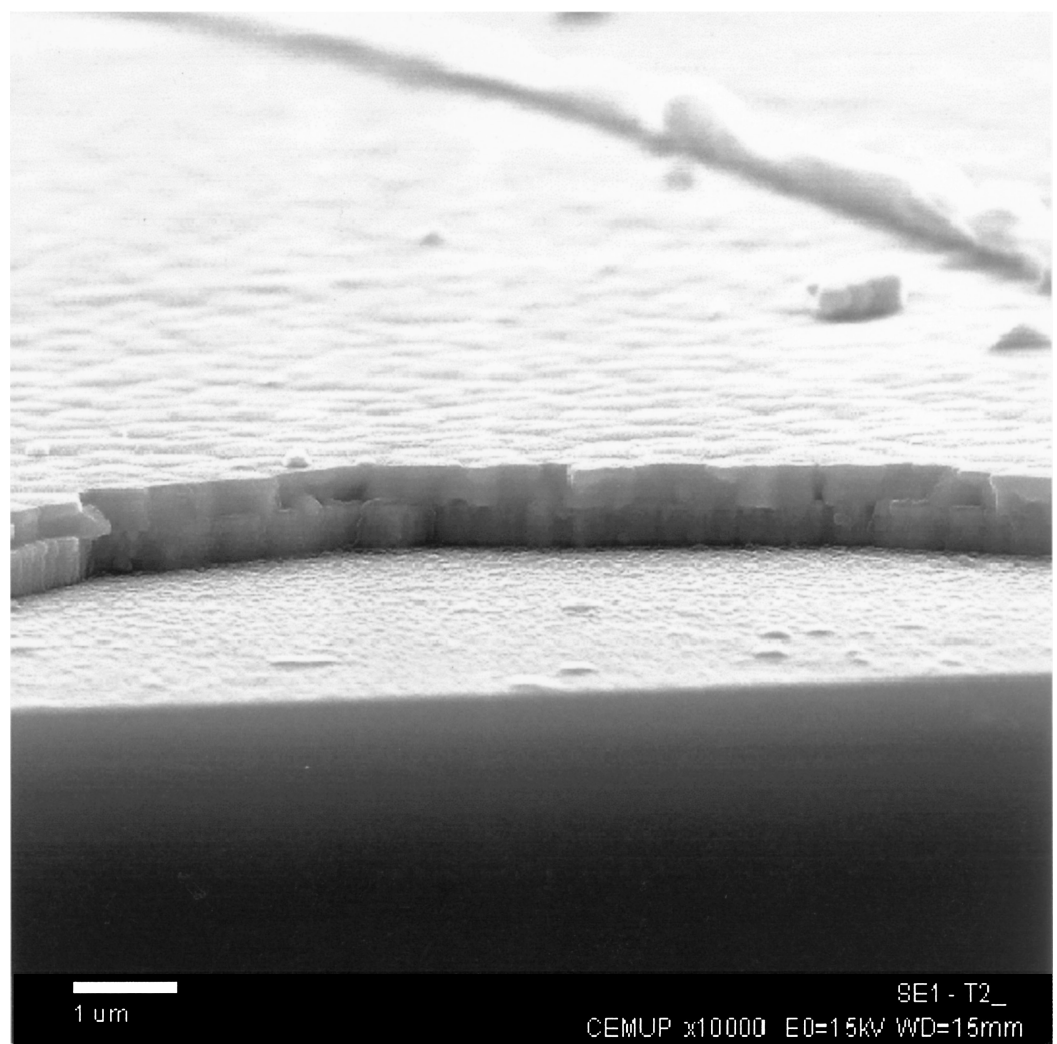

Figure 8. Cross-section of a PZT film deposited over $\mathrm{SiO}_{2} / \mathrm{BPO}$ and crystallized by RTA at $650^{\circ} \mathrm{C}$.

deposited directly over silica and PZT crystallized by RTA at $650^{\circ} \mathrm{C}$ and for PZT deposited over Pt and crystallized in the furnace at $675^{\circ} \mathrm{C}$ for 15 min.

The results for the PZT films deposited on $\mathrm{Pt}$ and $\mathrm{Pt} / \mathrm{BPO}$ are better then the ones for films deposited over $\mathrm{SiO}_{2} / \mathrm{BPO}$ due to the PZT orientation which is (111) when the Pt is present and (101) in the absence of Pt. The remnant polarization for films deposited over Pt/BPO is very high $\left(44 \mu \mathrm{C} / \mathrm{cm}^{2}\right)$ but the coercive field is also high $(145 \mathrm{kV} / \mathrm{cm})$. The coercive field became comparable with the Pt/PZT films for samples made directly over $\mathrm{SiO}_{2} / \mathrm{BPO}$. 

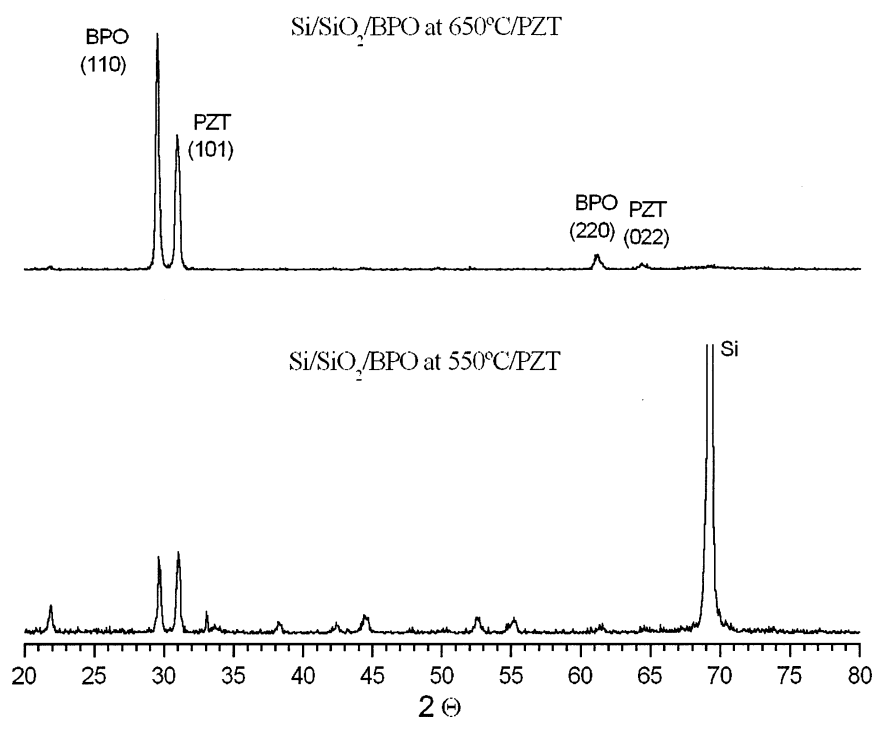

Figure 9. X-ray patterns for PZT films deposited over $\mathrm{SiO}_{2} / \mathrm{BPO}$ made in situ at $550^{\circ} \mathrm{C}$ and $650^{\circ} \mathrm{C}$ and crystallized by RTA at $650^{\circ} \mathrm{C}$.

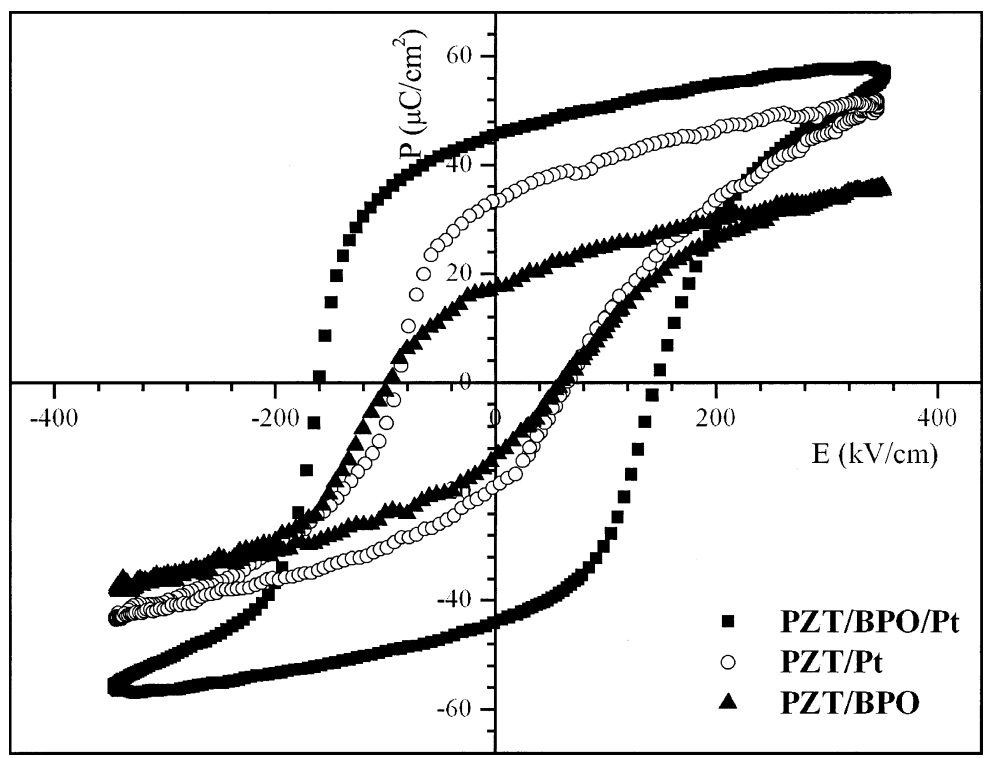

Figure 10. Hysteresis loops for PZT films deposited over Pt/BPO, BPO and Pt electrodes. 


\section{CONCLUSIONS}

In summary, barium metaplumbate thin films were deposited by laser ablation with a high deposition rate $(45 \mathrm{~nm} / \mathrm{min})$. BPO films made from targets sintered at low temperature are hygroscopic, but by using targets sintered at $1000^{\circ} \mathrm{C}$ stable, non-hygroscopic and conductive films could be obtained. The films deposited directly over silica were polycrystalline for temperatures above $500^{\circ} \mathrm{C}$, having a strong $(110)$ orientation only at $700^{\circ} \mathrm{C}$. When deposited over platinum, the BPO made at $2 \times 10^{-2}$ mbar of oxygen was oriented only in the (110) direction. For depositions made at 0.1 mbar of oxygen the films were oriented $(110)$ at $500^{\circ} \mathrm{C}$, changing to a mixed (222)/(200) orientation above $550^{\circ} \mathrm{C}$. The orientation of the BPO films was reflected on the PZT films deposited at room temperature over BPO and crystallized after the deposition. Two different thermal treatments were applied for crystallization of the PZT: furnace annealing and rapid thermal annealing, with the best results in terms of ferroelectric characteristics (higher remnant polarization, lower coercive field) being obtained with furnace annealing. Ferroelectric capacitors made with PZT crystallized by furnace annealing over BPO deposited at $600^{\circ} \mathrm{C}$ and $0.1 \mathrm{mbar}$ presented high values of remnant polarization $\left(44 \mu \mathrm{C} / \mathrm{cm}^{2}\right)$.

\section{REFERENCES}

[1] H. Ikushima and S. Hayakawa, Solid-State Electron 9, 921 (1966).

[2] R. D. Shanon and P. E. Bierstedt, J. Am. Ceram. Soc. 53, 635 (1970).

[3] Y. Hsieh and S. Fu, Ceramics International 18, 289 (1992).

[4] Y. R. Luo and J. M. Wu, Appl. Phys. Lett. 79, 3669 (2001).

[5] H. M. Duiker, P. D. Beale, J. F. Scott, C. A. Paz de Araujo, B. M. Melnick, J. D. Cuchlaro, and L. D. McMillan, J. Appl. Phys. 68, 5783 (1990).

[6] S. B. Desu, Phys. Stat. Sol. A 151, 467 (1995).

[7] G. Chao and J. Wu, Jpn. J. Appl. Phys. 40, 2417 (2001).

[8] M. S. Chen, T. B. Wu, and J. M. Wu, Appl. Phys. Lett. 68, 1430 (1996),

[9] M. S. Chen, J. M. Wu, and T. B. Wu, Jpn. J. Appl. Phys. 34, 4870 (1995).

[10] T. Morimoto, O. Hidaka, K. Yamakawa, O. Arisumi, H. Kanaya, T. Iwamoto, Y. Kumura, I. Kunishima, and S. Tanaka, Jpn. J. Appl. Phys. 39, 2110 (2000).

[11] R. Ramesh, T. Sands, V. G. Keramidas, and D. K. Fork, Mat. Res. Soc. Symp. Proc. 310, 195 (1993). 